\title{
Gene Polymorphisms Involved in Folate Metabolism and DNA Methylation with the Risk of Head and Neck Cancer
}

\author{
Tialfi Bergamin de Castro ${ }^{1}$, Gabriela Helena Rodrigues-Fleming ${ }^{1}$, Juliana \\ Garcia de Oliveira-Cucolo', Jéssika Nunes Gomes da Silva ${ }^{1}$, Fabia Pigatti \\ Silva $^{1}$, Luiz Sérgio Raposo ${ }^{2}$, José Victor Maniglia ${ }^{2}$, Érika Cristina Pavarino ${ }^{1}$, \\ Lidia Maria Rebolho Batista Arantes ${ }^{1}$, Ana Lívia Silva Galbiatti-Dias, \\ Eny Maria Goloni-Bertollo ${ }^{1 *}$
}

\begin{abstract}
Background: Folate is essential for DNA synthesis, repair, and methylation. Polymorphisms in genes associated with folate metabolism may alter these processes and, consequently, modulate cancer development. Aim: We aimed to assess DNMT3B -149C/T(rs2424913), DNMT3B -283T/C (rs6087990), DNMT3B -579G/T(rs2424909), DHFR 19-pb ins/del (rs70991108), SHMT1 1420C/T (rs1979277), and TYMS 28-bp tandem repeat (rs34743033) polymorphisms with risk of head and neck cancer. Methods: A case-control study was conducted in 1,086 Brazilian individuals. Real-time and conventional polymerase chain reactions-PCR were performed for genotyping the polymorphisms. Results: The single nucleotide polymorphism (SNP), $D N M T 3 B-283 T / C$, revealed a higher risk of head and neck squamous cell carcinoma (HNSCC) when compared with the $\mathrm{C}$ group in the codominant $(\mathrm{p}<0.001)$, dominant $(\mathrm{p}<0.001)$, and overdominant $(\mathrm{p}=0.001)$ models for T/C and C/C genotypes. DNMT3B $-149 C / T$ and $D N M T 3 B-579 G / T$ revealed no association between groups in any model. The DHFR 19-pb ins/del polymorphism protected against HNSCC development compared to the $\mathrm{C}$ group by the codominant $(\mathrm{p}<0.001)$, dominant $(\mathrm{p}<0.001)$, and overdominant $(\mathrm{p}<0.001)$ models. In the TYMS, the $3 \mathrm{R} / 3 \mathrm{R}$ genotype had a protective effect against HNSCC development compared with the $\mathrm{C}$ group by the recessive models ( $\mathrm{p}=0.009)$. In contrast, SHMT1 $1420 \mathrm{C} / \mathrm{T}$ presented no association between the HNSCC and C groups. DHFR $19-\mathrm{pb}$ ins/del polymorphisms protected against oral cavity cancer $(\mathrm{p}=0.003)$, and only TYMS-28 3R/3R decreased the risk of tumor progression ( $\mathrm{p}=0.023$ ). In the Kaplan-Meier curve, an association was found between DHFR ins/ins and TYMS - $283 R$ carriers with respect to relapse-free time; further, DNMT3B -579 T and TYMS-28 $2 R / 2 R$ carriers had longer survival times. Conclusion: DNMT3B -283T/C is associated with higher risk, whereas DHFR 19-pb ins/del and TYMS $283 R / 3 R$ protect against head and neck cancer. We also highlighted the association of $T Y M S 3 R / 3 R$ genotype carriers with relapse-free cancer protection and survival time.
\end{abstract}

Keywords: Head and neck cancer- folate- DNA methylation- polymorphism

Asian Pac J Cancer Prev, 21 (12), 3751-3759

\section{Introduction}

Presently, head and neck cancer is considered the fifth most common type of cancer worldwide and is associated with a high mortality rate when diagnosed in advanced stages. In 2020, 834,860 new cases of this neoplasm were estimated (IARC, 2019). This cancer comprises a heterogeneous group of tumors that originate in lining epithelium squamous cells of the upper digestive tract, including the lip, oral cavity, nasal cavity, paranasal sinus, pharynx, and larynx (Chow, 2020).

Elderly males are mostly affected (Chow, 2020; Wang et al., 2017). The main risk factors include tobacco and alcohol consumption, viral infections, particularly with the Epstein-Barr virus and human papillomavirus subtypes 16 and 18, as well as deficiencies or imbalances in vitamins and micronutrients such as folate, vitamins A, C, and E, zinc, and selenium (Fan et al., 2017). Smoking and alcohol consumption together increase the risk of this cancer, particularly in the oral cavity and pharynx, as cigarettes have approximately 4,700 chemical substances, of which at least 50 are carcinogenic; frequent alcohol consumption prevents epithelial cells forming the protective barrier against external agents, thus permitting easy entry of 
carcinogens, thereby forming adducts of DNA that are not recognized during DNA replication and repair (Wang et al., 2017).

Folate or vitamin B plays a pivotal role in one-carbon metabolism, and generally low levels can be associated with the absence of methylation and DNA repair, thereby promoting carcinogenesis (Pieroth et al., 2018). Thus, several functional gene polymorphisms linked to folate metabolism can cause an imbalance in methylation reactions, as well as free nucleotides for DNA synthesis and repair (Coppedè et al., 2019).

In most tumor models, higher intake of folate might decrease the risk of cancer development, as observed in oropharyngeal (Galeone et al., 2015), esophageal (Ni et al., 2019; Tio et al., 2014), pancreatic (Liu et al., 2017), cervical (Zhou and Meng, 2016), and breast cancer (Zeng et al., 2020); however, an inverse association can be seen in some tumor models, such as head and neck (Fanidi et al., 2015) and prostate cancers (Tio et al., 2014).

Thus, considering the contradictory results and genetic heterogeneity of the Brazilian population, it is important to evaluate the role of certain folate polymorphisms for susceptibility to head and neck carcinogens. Here, we aimed to investigate the association of polymorphisms DNMT3B -149C/T (rs2424913), DNMT3B -283T/C (rs6087990), DNMT3B -579G/T (rs2424909), DHFR 19pb ins/del (rs70991108), SHMT1 1420C/T (rs1979277), and TYMS 28-bp tandem repeat (rs34743033) with the risk of head and neck cancer.

\section{Materials and Methods}

\section{Ethics Statement}

The Research Ethics Committee of São José do Rio Preto Medical School (FAMERP) in São José do Rio Preto, São Paulo, Brazil, approved this study (Registration Number 013/2012), and written informed consent for the collection of biological material was obtained from all individuals.

\section{Subjects and Samples}

This was a case-control study. The case groups included 378 patients (337 men and 41 women; mean age, 59 years) with a confirmed histopathological diagnosis of cancer. The disease-free control group (C) included 708 Brazilian blood donors (517 men and 191 women; mean age, 47 years), without cancer diagnoses according to government guidelines for donated blood (http://bvsms.saude.gov.br/bvs/publicacoes/qualidade_ sangue.pdf). DNA was obtained from the leukocytes from peripheral blood samples of all participants (case and control; total: 1086), and was genotyped for folate polymorphisms [DNMT3B -149C $>T$ (rs2424913), DNMT3B -283T $>C$ (rs6087990), DNMT3B -579G $>T$ (rs2424909), DHFR 19-pb ins/del (rs70991108), SHMT1 1420C $>T$ (rs1979277), and TYMS 28-bp tandem repeat (rs34743033)].

Individuals were classified as having early stage (T0, $\mathrm{T} 1$, and $\mathrm{T} 2 ; \mathrm{N} 0$ and $\mathrm{M} 0$ ) and advanced stage tumors (T3 and T4; N1, N2, N3, and M1) based on their tumor, node, and metastasis (TNM) staging. The case and control group participants were interviewed to obtain their demographic and lifestyle data. Those who smoked more than 100 cigarettes in their lifetime were considered as tobacco consumers and those who consumed four doses of alcohol per week were considered as alcohol consumers.

\section{Polymorphism Genotyping}

DNA was extracted from the peripheral blood following a previously published protocol (Miller et al., 1988 ) with certain modifications (using Ficoll-Paque ${ }^{\mathrm{TM}}$ PLUS to separate blood components). The DNMT3B -149C/T (rs2424913), DNMT3B -283T/C (rs6087990), and SHMT1 1420C/T (rs1979277) polymorphisms were detected via a real-time polymerase chain reaction (PCR) for allelic discrimination using the Step One PlusTM Real-Time PCR System equipment (Applied Biosystems, USA), whereas DNMT3B -579G/T (rs2424909) was detected via PCR-RFLP (PCR-Restriction Fragment Length Polymorphism), and allele-specific PCR was used to assess the DHFR 19-pb ins/del (rs70991108) and TYMS 28-bp tandem repeat (rs34743033). For both PCR techniques, the reaction solution contained the following: $1 \times$ buffer, $15.3 \mu \mathrm{L}$ of ultrapure $\mathrm{H} 2 \mathrm{O}, 2.0 \mu \mathrm{L}$ $(0.10 \mu \mathrm{mol} / \mathrm{L})$ of dNTPs, $0.5 \mu \mathrm{L}(25 \mathrm{mmol} / \mathrm{L})$ of $\mathrm{MgCl} 2$, $1.25 \mu \mathrm{L}$ of each primer $(25 \mathrm{mmol} / \mathrm{L}), 0.2 \mu \mathrm{L}(1 \mathrm{U})$ of Taq DNA polymerase, and $200 \mathrm{ng}$ of genomic DNA. The PCR amplification products were visualized on a $3 \%$ agarose gel (Invitrogen ${ }^{\mathbb{R}}$ ) with ethidium bromide in the presence of a $100 \mathrm{bp}$ molecular marker.

\section{Statistical Analysis}

SNPStats software was used to calculate the odds ratios (ORs) and 95\% confidence intervals (CIs) for the risk associations between polymorphisms and head and neck cancer (Solé et al., 2006). The multiple logistic regression models were adjusted for age, gender, drinking, and smoking habits. The effect of the polymorphisms was evaluated in the models as (1) codominant (heterozygous vs. wild-type homozygous and polymorphic homozygous vs. wild-type homozygous); (2) dominant (heterozygous + polymorphic homozygous vs. wild-type homozygous); (3) recessive (polymorphic homozygous vs. wild-type homozygous + heterozygous); (4) overdominant (heterozygous vs. wild-type homozygous + polymorphic homozygous); or (5) log-additive (polymorphic homozygous with 2 + heterozygous vs. wild-type homozygous). Statistical analyses were performed using GraphPad Prism version 5.0 (GraphPad Software, Inc., USA) and SNPstats (https:// www.snpstats.net/start.htm) (Solé et al., 2006). The haplotype frequencies of DNMT3B were inferred using the Haploview program, version 4.0 (Barrett, 2009). A probability level (p) of $<0.05$ was considered to indicate statistical significance.

\section{Results}

The DNMT3B -149C>T (rs2424913) was not in Hardy-Weinberg equilibrium (HWE) in the case group (p < 0.001); DNMT3B -579G>T (rs2424909), DHFR 19-pb ins/del (rs70991108), and TYMS 28-bp tandem repeat (rs34743033) were not in HWE in the case 
Table 1. Multiple Logistic Regression of DNMT3B -149 C/T, -283T/C, and -579G/T , DHFR, SHMT, and TYMS Polymorphisms in Individuals Free of Disease (Control-C) and Head and Neck Squamous Cell Carcinoma (HNSCC) Groups

\begin{tabular}{|c|c|c|c|c|}
\hline Polymorphisms & Genotypes & Control, n (\%) & Case, $\mathrm{n}(\%)$ & OR $(95 \% \mathrm{CI})$ \\
\hline \multicolumn{5}{|c|}{ DNMT3B -149C/T (rs2424913) } \\
\hline \multirow[t]{3}{*}{ Codominant } & $\mathrm{C} / \mathrm{C}$ & $131(23.8)$ & $75(22.8)$ & 1 \\
\hline & $\mathrm{C} / \mathrm{T}$ & $287(52.1)$ & $168(51.1)$ & $1.01(0.65-1.55)$ \\
\hline & $\mathrm{T} / \mathrm{T}$ & $133(24.1)$ & $86(26.1)$ & $1.14(0.69-1.87)$ \\
\hline \multirow[t]{2}{*}{ Dominant } & $\mathrm{C} / \mathrm{C}$ & $131(23.8)$ & $75(22.8)$ & 1 \\
\hline & $\mathrm{C} / \mathrm{T}-\mathrm{T} / \mathrm{T}$ & $420(76.2)$ & $254(77.2)$ & $1.05(0.70-1.58)$ \\
\hline \multirow[t]{2}{*}{ Recessive } & $\mathrm{C} / \mathrm{C}-\mathrm{CT}$ & $418(75.9)$ & $243(73.9)$ & 1 \\
\hline & $\mathrm{T} / \mathrm{T}$ & $133(24.1)$ & $86(26.1)$ & $1.13(0.76-1.69)$ \\
\hline \multirow[t]{2}{*}{ Overdominant } & $\mathrm{C} / \mathrm{C}-\mathrm{T} / \mathrm{T}$ & $264(47.9)$ & $161(48.9)$ & 1 \\
\hline & $\mathrm{C} / \mathrm{T}$ & $287(52.1)$ & $168(51.1)$ & $0.94(0.66-1.34)$ \\
\hline Additive & --- & --- & --- & $1.07(0.83-1.37)$ \\
\hline \multicolumn{5}{|c|}{$D N M T 3 B-283 \mathrm{~T} / \mathrm{C}(\mathrm{rs} 6087990)^{\mathrm{b}}$} \\
\hline \multirow[t]{3}{*}{ Codominant } & $\mathrm{T} / \mathrm{T}$ & $153(26.3)$ & $43(13.6)$ & 1 \\
\hline & $\mathrm{T} / \mathrm{C}$ & $278(48.2)$ & $194(61.2)$ & $2.58(1.59-4.18)$ \\
\hline & $\mathrm{C} / \mathrm{C}$ & $146(25.3)$ & $80(25.2)$ & $1.86(1.08-3.22)$ \\
\hline \multirow[t]{2}{*}{ Dominant } & $\mathrm{T} / \mathrm{T}$ & $153(26.5)$ & $43(13.6)$ & 1 \\
\hline & $\mathrm{T} / \mathrm{C}-\mathrm{CC}$ & $424(73.5)$ & $274(86.4)$ & $2.32(1.46-3.69)$ \\
\hline \multirow[t]{2}{*}{ Recessive } & $\mathrm{T} / \mathrm{T}-\mathrm{T} / \mathrm{C}$ & $431(74.7)$ & $237(74.8)$ & 1 \\
\hline & $\mathrm{C} / \mathrm{C}$ & $146(25.3)$ & $80(25.2)$ & $0.93(0.62-1.40)$ \\
\hline \multirow[t]{2}{*}{ Overdominant } & $\mathrm{T} / \mathrm{T}-\mathrm{C} / \mathrm{C}$ & $299(51.8)$ & $123(38.8)$ & 1 \\
\hline & $\mathrm{T} / \mathrm{C}$ & $278(48.2)$ & $194(61.2)$ & $1.81(1.26-2.59)$ \\
\hline Additive & --- & --- & --- & $1.29(0.99-1.68)$ \\
\hline \multicolumn{5}{|c|}{$D N M T 3 B-579 \mathrm{G} / \mathrm{T}(\mathrm{rs} 2424909)^{\mathrm{c}}$} \\
\hline \multirow[t]{3}{*}{ Codominant } & $\mathrm{G} / \mathrm{G}$ & $193(35.2)$ & $110(34.8)$ & 1 \\
\hline & $\mathrm{G} / \mathrm{T}$ & $220(40.1)$ & $126(39.9)$ & $0.88(0.58-1.34)$ \\
\hline & $\mathrm{T} / \mathrm{T}$ & $135(24.6)$ & $80(25.3)$ & $0.88(0.55-1.42)$ \\
\hline \multirow[t]{2}{*}{ Dominant } & $\mathrm{G} / \mathrm{G}$ & $193(35.2)$ & $110(34.8)$ & 1 \\
\hline & $\mathrm{G} / \mathrm{T}-\mathrm{T} / \mathrm{T}$ & $355(64.8)$ & $206(65.2)$ & $0.88(0.60-1.29)$ \\
\hline \multirow[t]{2}{*}{ Recessive } & G/G-G/T & $413(75.4)$ & $236(74.7)$ & 1 \\
\hline & $\mathrm{T} / \mathrm{T}$ & $135(24.6)$ & $80(25.3)$ & $0.95(0.62-1.44)$ \\
\hline \multirow[t]{2}{*}{ Overdominant } & $\mathrm{G} / \mathrm{G}-\mathrm{T} / \mathrm{T}$ & $328(59.9)$ & $190(60.1)$ & 1 \\
\hline & $\mathrm{G} / \mathrm{T}$ & $220(40.1)$ & $126(39.9)$ & $0.93(0.64-1.34)$ \\
\hline Additive & --- & --- & --- & $0.94(0.74-1.18)$ \\
\hline \multicolumn{5}{|c|}{ DHFR 19-pb ins/del (rs70991108) ${ }^{\mathrm{d}}$} \\
\hline \multirow[t]{3}{*}{ Codominant } & ins/ins & $145(28.0)$ & $112(37.3)$ & 1 \\
\hline & ins/del & $282(54.4)$ & $127(42.3)$ & $0.42(0.27-0.65)$ \\
\hline & del/del & $91(17.6)$ & $61(20.3)$ & $0.70(0.40-1.22)$ \\
\hline \multirow[t]{2}{*}{ Dominant } & ins/ins & $145(28.0)$ & $112(37.3)$ & 1 \\
\hline & ins/del-del/del & $373(72.0)$ & $188(62.7)$ & $0.48(0.32-0.73)$ \\
\hline \multirow[t]{2}{*}{ Recessive } & ins/ins-ins/del & $427(82.4)$ & $239(79.7)$ & 1 \\
\hline & del/del & $91(17.6)$ & $61(20.3)$ & $1.19(0.74-1.94)$ \\
\hline \multirow[t]{2}{*}{ Overdominant } & ins/ins-del/del & $236(45.6)$ & $173(57.7)$ & 1 \\
\hline & ins/del & $282(54.4)$ & $127(42.3)$ & $0.48(0.32-0.71)$ \\
\hline Additive & --- & --- & --- & $0.76(0.58-1.01)$ \\
\hline \multicolumn{5}{|c|}{ SHMT1 1420C/T (rs1979277) } \\
\hline \multirow[t]{3}{*}{ Codominant } & $\mathrm{C} / \mathrm{C}$ & $280(53.3)$ & $166(49.5)$ & 1 \\
\hline & $\mathrm{C} / \mathrm{T}$ & $196(37.3)$ & $139(41.5)$ & $1.07(0.73-1.56)$ \\
\hline & $\mathrm{T} / \mathrm{T}$ & $49(9.3)$ & $30(9.0)$ & $0.68(0.36-1.28)$ \\
\hline
\end{tabular}


Table 1. Continued

\begin{tabular}{|c|c|c|c|c|}
\hline Polymorphisms & Genotypes & Control, n (\%) & Case, n (\%) & OR $(95 \% \mathrm{CI})$ \\
\hline \multirow[t]{2}{*}{ Dominant } & $\mathrm{C} / \mathrm{C}$ & $280(53.3)$ & $166(49.5)$ & 1 \\
\hline & $\mathrm{C} / \mathrm{T}-\mathrm{T} / \mathrm{T}$ & $245(46.7)$ & $169(50.5)$ & $0.98(0.68-1.40)$ \\
\hline \multirow[t]{2}{*}{ Recessive } & $\mathrm{C} / \mathrm{C}-\mathrm{C} / \mathrm{T}$ & $476(90.7)$ & $305(91)$ & 1 \\
\hline & $\mathrm{T} / \mathrm{T}$ & $49(9.3)$ & $30(9.0)$ & $0.66(0.36-1.21)$ \\
\hline \multirow[t]{2}{*}{ Overdominant } & $\mathrm{C} / \mathrm{C}-\mathrm{T} / \mathrm{T}$ & $329(62.7)$ & $196(58.5)$ & 1 \\
\hline & $\mathrm{C} / \mathrm{T}$ & $196(37.3)$ & $139(41.5)$ & $1.14(0.79-1.64)$ \\
\hline Additive & --- & --- & --- & $0.91(0.69-1.19)$ \\
\hline \multicolumn{5}{|c|}{ TYMS 28-bp tandem repeat (rs34743033) } \\
\hline \multirow[t]{3}{*}{ Codominant } & $2 \mathrm{R} / 2 \mathrm{R}$ & $123(22.9)$ & $85(24.9)$ & 1 \\
\hline & $2 \mathrm{R} / 3 \mathrm{R}$ & $320(59.5)$ & $218(63.9)$ & $1.11(0.71-1.72)$ \\
\hline & $3 R / 3 R$ & $95(17.7)$ & $38(11.1)$ & $0.55(0.30-1.01)$ \\
\hline \multirow[t]{2}{*}{ Dominant } & $2 \mathrm{R} / 2 \mathrm{R}$ & $123(22.9)$ & $85(24.9)$ & 1 \\
\hline & $2 R / 3 R-3 R / 3 R$ & $415(77.1)$ & $256(75.1)$ & $0.96(0.63-1.48)$ \\
\hline \multirow[t]{2}{*}{ Recessive } & $2 R / 2 R-2 R / 3 R$ & $443(82.3)$ & $303(88.9)$ & 1 \\
\hline & $3 \mathrm{R} / 3 \mathrm{R}$ & $95(17.7)$ & $38(11.1)$ & $0.51(0.30-0.85)$ \\
\hline \multirow[t]{2}{*}{ Overdominant } & $2 \mathrm{R} / 2 \mathrm{R}-3 \mathrm{R} / 3 \mathrm{R}$ & $218(40.5)$ & $123(36.1)$ & 1 \\
\hline & $2 \mathrm{R} / 3 \mathrm{R}$ & $320(59.5)$ & $218(63.9)$ & $1.40(0.96-2.03)$ \\
\hline Additive & --- & --- & --- & $0.78(0.58-1.05)$ \\
\hline
\end{tabular}

Odds Ratio (OR) adjusted for age, gender, alcohol, smoking habits, and polymorphisms; significant $\mathrm{p}$ values, $\mathrm{p}<0.05$. ${ }^{\mathrm{a}}$ Amplification was performed for 552 individuals in the control and 329 in the case groups; ${ }^{b} 577$ individuals in the control and 317 in the case groups; 548 individuals in the control and in the case groups; ${ }^{\mathrm{d}} 518$ individuals in the control and 300 in the case groups; 525 individuals in the control and 335 in the case groups; and 538 individuals in the control and 341 in the case groups.

$(\mathrm{p}<0.001, \mathrm{p}=0.032, \mathrm{p}<0.001$, respectively) and control groups $(\mathrm{p}<0.001, \mathrm{p}=0.026$, and $\mathrm{p}<0.001)$. The other polymorphisms complied with HWE in both the case and control groups.

The sample group presented a median age of 51 years, and male gender was prevalent in the case $(89.0$

Table 2. Association of the DNMT3B (-149C/T, -283T/C, -579G/T), DHFR 19-pb ins/del, SHMT1 1420C/T, and TYMS 28-bp Tandem Repeat Polymorphisms with the Primary Sites (Oral Cavity, Pharynx, and Larynx) in Head and Neck Cancer Group.

\begin{tabular}{|c|c|c|c|c|c|c|}
\hline \multirow{2}{*}{$\begin{array}{l}\text { Polymorphisms } \\
\text { DNMT3B -149C/T (rs2424913)a }\end{array}$} & \multicolumn{2}{|c|}{ Oral cavity } & \multicolumn{2}{|c|}{ Pharynx } & \multicolumn{2}{|c|}{ Larynx } \\
\hline & $\mathrm{n}(\%)$ & OR (95 CI) & $\mathrm{n}(\%)$ & OR (95 CI) & $\mathrm{n}(\%)$ & OR (95 CI) \\
\hline $\mathrm{C} / \mathrm{C}$ & $28(22.0)$ & 1 & $15(21.0)$ & 1 & $27(24.0)$ & 1 \\
\hline $\mathrm{C} / \mathrm{T}-\mathrm{T} / \mathrm{T}$ & $98(78.0)$ & $1.09(0.68-1.73)$ & $50(79.0)$ & $1.16(0.63-2.12)$ & $85(76.0)$ & $0.98(0.61-1.58)$ \\
\hline \multicolumn{7}{|l|}{ DNMT3B -283T/C (rs6087990)b } \\
\hline $\mathrm{T} / \mathrm{T}$ & $16(13.0)$ & 1 & $9(15.0)$ & 1 & $15(14.0)$ & 1 \\
\hline $\mathrm{T} / \mathrm{C}-\mathrm{C} / \mathrm{C}$ & $108(87.0)$ & $2.43(1.39-4.25)$ & $53(85.0)$ & $2.12(1.02-4.41)$ & $90(86.0)$ & $2.16(1.21-3.85)$ \\
\hline \multicolumn{7}{|l|}{$D N M T 3 B-579 \mathrm{G} / \mathrm{T}(\mathrm{rs} 2424909) \mathrm{c}$} \\
\hline $\mathrm{G} / \mathrm{G}$ & $45(37.0)$ & 1 & $20(32.0)$ & 1 & $35(33.0)$ & 1 \\
\hline $\mathrm{G} / \mathrm{T}-\mathrm{T} / \mathrm{T}$ & $78(63.0)$ & $0.94(0.62-1.41)$ & $43(68.0)$ & $1.16(0.66-2.04)$ & $70(67.0)$ & $1.08(0.69-1.69)$ \\
\hline \multicolumn{7}{|c|}{ DHFR 19-pb ins/del $\quad($ rs70991108)d } \\
\hline ins/ins & $49(42.0)$ & 1 & $20(36.0)$ & 1 & $39(37.0)$ & 1 \\
\hline ins/del -del/del & $67(58.0)$ & $0.53(0.35-0.80)$ & $35(64.0)$ & $0.68(0.38-1.21)$ & $66(63.0)$ & $0.65(0.42-1.02)$ \\
\hline \multicolumn{7}{|l|}{ SHMT1 1420C/T (rs1979277) e } \\
\hline $\mathrm{C} / \mathrm{C}$ & $59(45.0)$ & 1 & $34(51.0)$ & 1 & $62(55.0)$ & 1 \\
\hline $\mathrm{C} / \mathrm{T}-\mathrm{T} / \mathrm{T}$ & $71(55.0)$ & $1.37(0.93-2.02)$ & $33(49.0)$ & $1.10(0.66-1.84)$ & $50(45.0)$ & $0.92(0.61-1.38)$ \\
\hline \multicolumn{7}{|c|}{ TYMS 28-bp tandem repeat(rs34743033)f } \\
\hline $2 \mathrm{R} / 2 \mathrm{R}$ & $38(28.0)$ & 1 & $11(16.0)$ & 1 & $26(23.0)$ & 1 \\
\hline $2 \mathrm{R} / 3 \mathrm{R}-3 \mathrm{R} / 3 \mathrm{R}$ & $100(72.0)$ & $0.78(0.51-1.19)$ & $56(84.0)$ & $1.50(0.76-2.97)$ & $85(77.0)$ & $0.96(0.59-1.57)$ \\
\hline
\end{tabular}

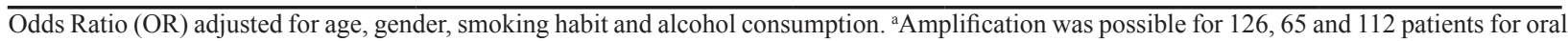
cavity, pharynx and larynx, respectively; ${ }^{\mathrm{b}} 124,62$ and 105 patients for oral cavity, pharynx and larynx, respectively; ${ }^{\mathrm{c}} 123,63$ and 105 patients for oral cavity, pharynx and larynx, respectively; ${ }^{\mathrm{d}} 116,55$ and 105 patients for oral cavity, pharynx and larynx, respectively; ${ }^{\mathrm{e}} 130,67$ and 112 patients for oral cavity, pharynx and larynx, respectively; ${ }^{\mathrm{f}} 138,67$ and 111 patients for oral cavity, pharynx and larynx, respectively. 

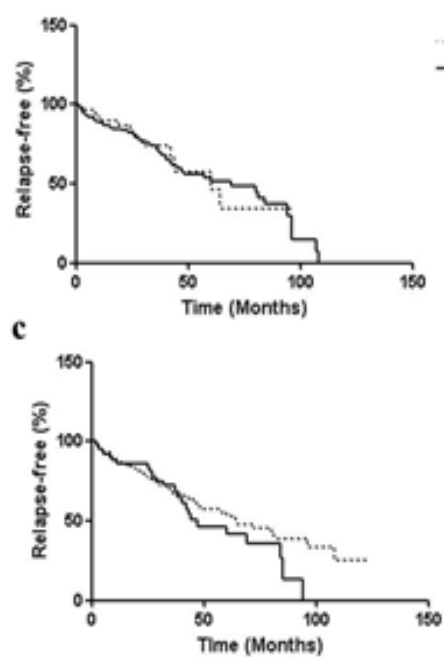

e

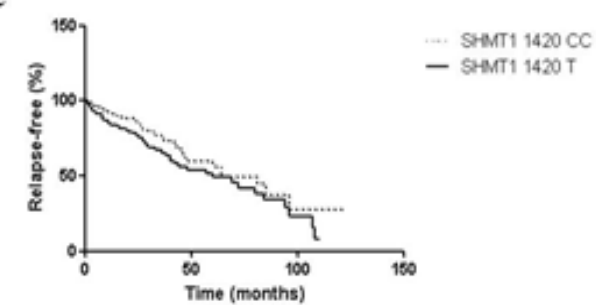

b
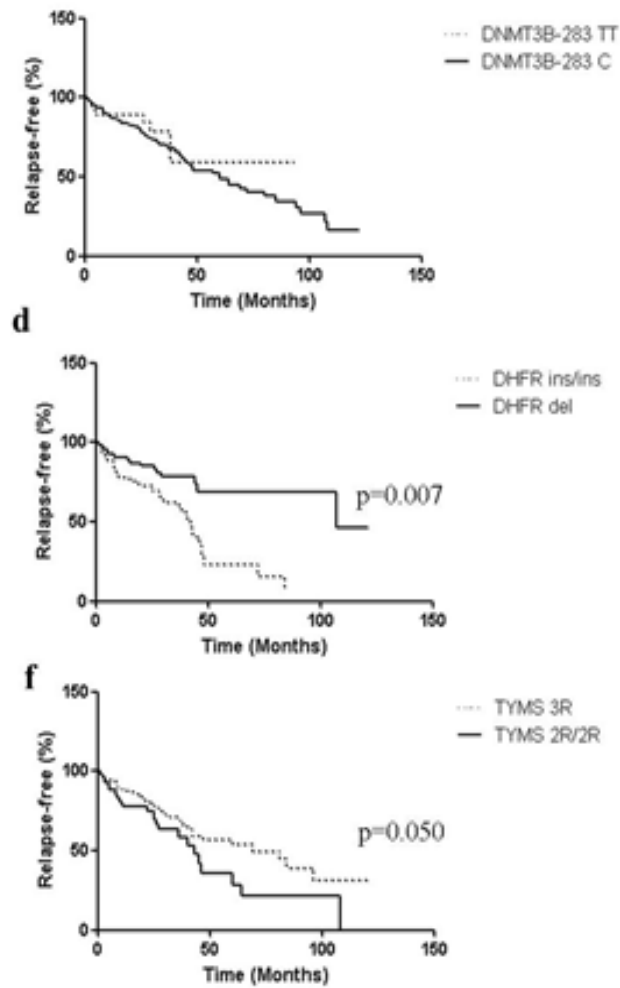

Figure 1. Kaplan-Meier Curves for Relapse-Free Time in Head and Neck Cancer Group. Comparison between (a) DNMT3B -149C/T: wild-type C/C and T polymorphic carriers, $\mathrm{p}=0.741$; (b) DNMT3B -283T/C: wild-type T/T and C polymorphic carriers, $\mathrm{p}=0.479$; (c) DNMT3B $-579 \mathrm{G} / \mathrm{T}$ : wild-type $\mathrm{G} / \mathrm{G}$ and T polymorphic carriers, $\mathrm{p}=0.413$; (d) DHFR 19-pb ins/del: wild-type ins/ins and del polymorphic carriers, $\mathrm{p}=0.007$; (e) SHMT1 1420C/T: wild-type C/C and T polymorphic carriers, $\mathrm{p}=0.068$; and (f) TYMS 28-bp tandem repeat: $3 \mathrm{R}$ carriers and $2 \mathrm{R} / 2 \mathrm{R}$ genotype, $\mathrm{p}=0.050$. Log-rank (Mantel-Cox) test.

Table 3. Association of the DNMT3B (-149C/T, $-283 \mathrm{~T} /$ C, -579G/T), DHFR 19-pb ins/del, SHMT1 1420C/T, and TYMS 28-bp Tandem Repeat Polymorphisms with Tumor, Nodes, and Metastasis (TNM) Staging System in Patients with Head and Neck Cancer

\begin{tabular}{|c|c|c|c|}
\hline \multirow[t]{2}{*}{ Polymorphisms } & \multicolumn{3}{|c|}{ Tumor progression (TNM) } \\
\hline & Early & Advanced & OR $(95 \mathrm{CI})$ \\
\hline \multicolumn{4}{|c|}{ DNMT3B -149C/T (rs2424913) } \\
\hline $\mathrm{C} / \mathrm{C}$ & $40(22.9)$ & $32(23.2)$ & 1 \\
\hline $\mathrm{C} / \mathrm{T}-\mathrm{T} / \mathrm{T}$ & $135(77.1)$ & $106(76.8)$ & $0.99(0.57-1.69)$ \\
\hline \multicolumn{4}{|c|}{ DNMT3B $-283 \mathrm{~T} / \mathrm{C}(\mathrm{rs} 6087990)^{\mathrm{b}}$} \\
\hline $\mathrm{T} / \mathrm{T}$ & $17(10.2)$ & $25(18.2)$ & 1 \\
\hline $\mathrm{T} / \mathrm{C}-\mathrm{C} / \mathrm{C}$ & $149(89.8)$ & $112(81.8)$ & $0.55(0.28-1.07)$ \\
\hline \multicolumn{4}{|c|}{ DNMT3B -579G/T (rs2424909) ${ }^{\mathrm{c}}$} \\
\hline $\mathrm{G} / \mathrm{G}$ & $62(37.1)$ & $44(33.1)$ & 1 \\
\hline $\mathrm{G} / \mathrm{T}-\mathrm{T} / \mathrm{T}$ & $105(62.9)$ & $89(66.9)$ & $1.18(0.73-1.93)$ \\
\hline \multicolumn{4}{|c|}{ DHFR 19-pb ins/del (rs70991108) ${ }^{\mathrm{d}}$} \\
\hline ins/ins & $67(40.4)$ & $40(32.5)$ & 1 \\
\hline ins/del-del/del & $99(59.6)$ & $83(67.5)$ & $1.50(0.91-2.46)$ \\
\hline \multicolumn{4}{|c|}{ SHMT1 $1420 \mathrm{C} / \mathrm{T}(\mathrm{rs} 1979277)^{\mathrm{e}}$} \\
\hline $\mathrm{C} / \mathrm{C}$ & $89(50.0)$ & $73(51.8)$ & 1 \\
\hline $\mathrm{C} / \mathrm{T}-\mathrm{T} / \mathrm{T}$ & $89(50.0)$ & $68(48.2)$ & $0.92(0.59-1.45)$ \\
\hline
\end{tabular}

Odds Ratio (OR) adjusted for age, gender, smoking habit and alcohol consumption. ${ }^{\mathrm{a}} 313$ patients; ${ }^{\mathrm{b}} 303$ patients; $\mathrm{c} 300$ patients; $\mathrm{d} 362$ patients; e319 patients; f326patients.
$\%)$ and control $(73.0 \%)$ groups. The multiple logistic regression analysis that evaluated the sociodemographic characteristics and risk factors indicated that the male gender $(\mathrm{OR}=3.03 ; 95 \% \mathrm{CI}=2.11-4.37 ; \mathrm{p}<0.001)$, age $\geq 51$ years $(\mathrm{OR}=13.16 ; 95 \% \mathrm{CI} \%=9.66-17.94 ; \mathrm{p}<$ $0.001)$, smoking habit $(\mathrm{OR}=9.84 ; 95 \% \mathrm{CI}=7.04-13.77$; $\mathrm{p}<0.001)$, and alcohol consumption $(\mathrm{OR}=3.18 ; 95 \%$ $\mathrm{CI}=2.38-4.24 ; \mathrm{p}<0.001)$ were associated with greater susceptibility to the development of this neoplasia when compared to the control group .

DNMT3B -283T/C (rs6087990) SNP was associated with a higher risk of head and neck squamous cell carcinoma (HNSCC) on comparison with the $\mathrm{C}$ group in the codominant model for both $\mathrm{T} / \mathrm{C}$ and $\mathrm{C} / \mathrm{C}$ genotypes $(\mathrm{OR}=2.58 ; 95 \% \mathrm{CI}=1.59-4.18 ; \mathrm{p}<0.001$ and $\mathrm{OR}=$ $1.86 ; 1.08-3.22 ; \mathrm{p}<0.001$, respectively) and dominant $(\mathrm{OR}=2.32 ; 1.46-3.69 ; \mathrm{p}<0.001)$ and overdominant models $(\mathrm{OR}=1.81 ; 95 \% \mathrm{CI}=1.26-2.59 ; \mathrm{p}=0.001)$. The other two SNPs evaluated in this gene, DNMT3B -149C/T(rs2424913) and DNMT3B -579G/T (rs2424909), presented no association between groups in any model evaluated (Table 1).

DHFR 19-pb ins/del (rs70991108) was associated with a protective effect against HNSCC development compared to the $\mathrm{C}$ group by the codominant $(\mathrm{OR}=0.42 ; 95 \% \mathrm{CI}$ $=0.27-0.65 ; \mathrm{p}<0.001)$, dominant $(\mathrm{OR}=0.48 ; 95 \%$ $\mathrm{CI}=0.32-0.73 ; \mathrm{p}<0.001)$, and overdominant models $(\mathrm{OR}=0.48 ; 95 \% \mathrm{CI}=0.32-0.71 ; \mathrm{p}<0.001)$. Similar 
a
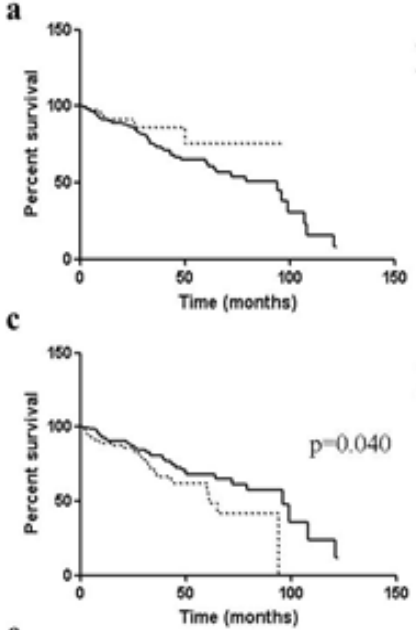

e

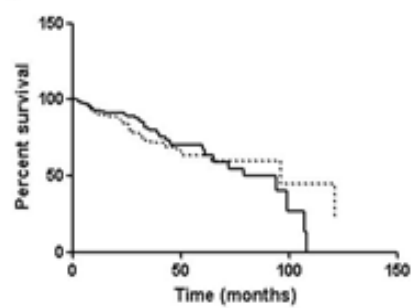

b

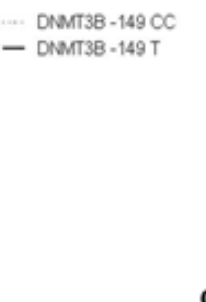

d

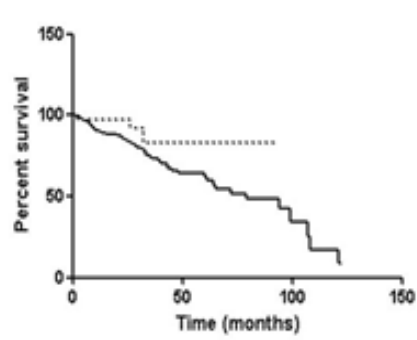

-.. DNMT3B-579G0 - DNMT3B-579T
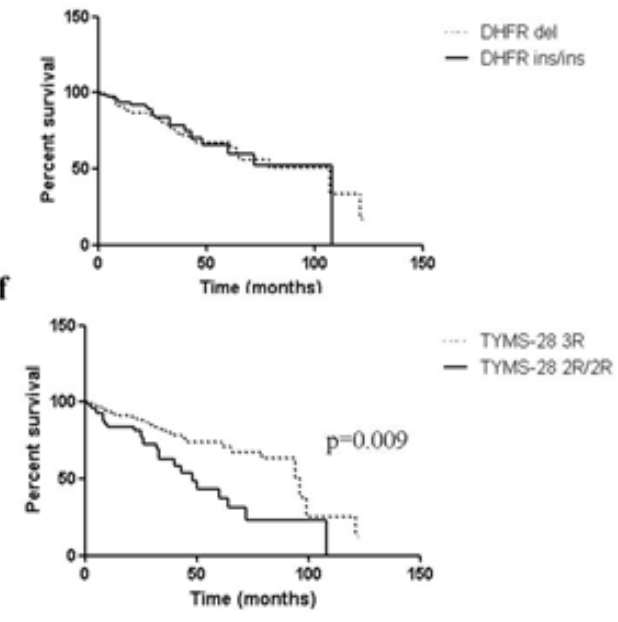

Figure 2. Kaplan-Meier Curves for Survival Time in Head and Neck Cancer Group. Comparison between (a) DNMT3B -149C/T: wild-type C/C and T polymorphic carriers, $\mathrm{p}=0.145$; (b) DNMT3B -283T/C: wild-type T/T and C polymorphic carriers, $\mathrm{p}=0.140$; (c) DNMT3B -579G/T: wild-type $\mathrm{G} / \mathrm{G}$ and $\mathrm{T}$ polymorphic carriers, $\mathrm{p}=0.040$; (d) DHFR 19-pb ins/del: wild-type ins/ins and del polymorphic carriers, $\mathrm{p}=0.742$; (e) SHMT1 1420C/T: wild-type C/C and T polymorphic carriers, $\mathrm{p}=0.784$; and (f) TYMS 28-bp tandem repeat: $3 \mathrm{R}$ carriers and 2R/2R genotype, $\mathrm{p}=0.009$. Log-rank (Mantel-Cox) test.

results were obtained for TYMS 28-bp tandem repeat (rs34743033), where the 3R/3R genotype was associated with a protective effect against HNSCC development when comparing the $\mathrm{C}$ group by the recessive model $(\mathrm{OR}=0.51 ; 95 \% \mathrm{CI}=0.30-0.85 ; \mathrm{p}=0.009)$. In fact, SHMT1 1420C/T (rs1979277) revealed no association when compared to the HNSCC and C groups (Table 1).

All polymorphisms were investigated to evaluate their association with the primary site. Thus, the present study demonstrated an association between the DNMT3B -283T/ $C S N P$ and an increased risk of cancer in the oral cavity $(\mathrm{OR}=2.436 ; 95 \% \mathrm{CI}=1.39-4.25 ; \mathrm{p}=0.001)$, pharynx $(\mathrm{OR}=2.12 ; 95 \% \mathrm{CI}=1.02-4.41 ; \mathrm{p}=0.045)$, and larynx $(\mathrm{OR}=2.16 ; 95 \% \mathrm{CI}=1.21-3.85 ; \mathrm{p}=0.006)$; however, DHFR 19-pb ins/del polymorphisms were associated with a protective effect against oral cavity cancer $(\mathrm{OR}=0.53$; 95\% CI $=0.35-0.80 ; \mathrm{p}=0.003$ ) (Table 2).

With regards to the association of polymorphisms with the TNM staging system, only TYMS-28 3R/3R SNP was associated with decreased risk of tumor progression (OR $=0.55 ; 95 \% \mathrm{CI}=0.33-0.93 ; \mathrm{p}=0.023$ ) (Table 3 ).

The DNMT3B haplotypes analyses revealed a higher frequency of the alleles DNMT3B -149C, 283C, and $579 \mathrm{~T}$ in the case group than in the control group $(33.0 \%$ and $25.4 \%$, respectively; $\mathrm{p}<0.001$ ), as well as that of DNMT3B -149T, 283T, and 579G (34.3\% and 29.4\%, respectively; $\mathrm{p}=0.031)$; however, contradictory results were observed for DNMT3B -149T, 283C, and 579T, (3.0\% and $8.0 \%$, respectively; $\mathrm{p}<0.001$ ), for DNMT3B $-149 \mathrm{~T}, 283 \mathrm{~T}$, and $579 \mathrm{~T}$ haplotype $(3.8 \%$ and $6.8 \%$, respectively; $\mathrm{p}=0.007$ ), and for $149 \mathrm{~T}, 283 \mathrm{C}$, and $579 \mathrm{G}$ haplotypes (3.3\% and $6.2 \%$ respectively; $p=0.007)$, which were more frequent in the control group than in the case group.

In another statistical analysis, the Kaplan-Meier curve indicated the relapse-free and survival time in allele carriers and noncarriers (Figure 1 and 2, respectively). An association was observed in relation to the relapsefree time between DHFR del carriers (median $=100 \%$ ) and DHFR ins/ins (median $=42 \%), p=0.027$, as well as, with the TYMS $-283 R$ carriers (median $=69 \%$ ) and TYMS $-282 R / 2 R($ median $=43 \%), \mathrm{p}=0.050$. For the survival time, an association was observed between the $D N M T 3 B-579 G / G($ median $=61 \%)$ and $D N M T 3 B-579$ $T$ carriers (median $=96 \%), \mathrm{p}=0.040$, as well as between TYMS $-282 R / 2 R$ (median $=48 \%$ ) and TYMS-28 $3 R$ carriers (median $=96 \%$ ), $\mathrm{p}=0.009$. For the other polymorphisms analyzed, no relationship was observed between the relapse-free and survival times.

\section{Discussion}

In this study, we found that the sociodemographic characteristics and risk factors indicated that the male gender, advanced age, smoking, and alcohol consumption were associated with greater susceptibility to cancer development when compared to the control group. Head and neck cancer has a multifactorial etiology and involves various risk factors.

In most countries, the rate at which men are affected is 
approximately two to five times higher than that of women, and this difference is presumably related to the adverse effects of carcinogens such as alcohol and tobacco, more commonly observed among men. Excessive consumption of carcinogens can affect nutrient absorption by the intestine, causing major nutritional deficiencies, and can modify the metabolic pathways, such as that of folate, which is essential for purine and pyrimidine synthesis and DNA methylation (Rettig and D'Souza, 2015). Moreover, the consumption of two or more cigarette packs along with four or more alcoholic drinks per day increases the risk of developing this neoplasia by 35 -fold (Canova et al., 2010).

Furthermore, the elderly are prone to cancer risk, with a median diagnosis age of approximately $60-70$, which is higher than the median age considered at risk in this study (Cohen et al., 2018).

Numerous studies have explored the association of DNMT3B polymorphisms and cancer risk but yielded conflicting results. One meta-analysis suggests that $D N M T 3 B-283 T / C$ and $D N M T 3 B-579 G / T$ may play a protective role against different types of cancers. Moreover, in the subgroup analysis, DNMT3B $-579 G / T$ appeared to contribute to decreased risk of lung and colorectal cancer, whereas DNMT3B $-149 \mathrm{C} / T$ was associated with a decreased risk of head and neck cancer (Zhang et al., 2015). Another systematic evaluation of cancer risk demonstrated that DNMT3B -149C/T, DNMT3B -283T/C, and $D N M T 3 B-579 G / T$ polymorphisms were observed as protective factors against cancer in the Asian population (Duan et al., 2015); however, in our study, the DNMT3B $-149 C / T$ and $-579 G / T$ SNPS did not contribute to the risk of head and neck cancer, whereas DNMT3B -283T/C might be a risk factor for head and neck carcinogenesis. Li et al., (2016) demonstrated that DNMT3B -283T/C (rs6087990) has a potential effect on gastric cancer initiation.

We found that DHFR 19-pb ins/del (rs70991108) and TYMS 28-bp tandem repeat (rs34743033) polymorphisms have a protective effect against head and neck cancer. Our study is the first to evaluate the association between a DHFR 19pb deletion polymorphism and the risk of this neoplasia. Evaluation in other cancer types reveals different results. Jokic et al., (2011) and Liu et al., (2013) demonstrated that DHFR deletion was not associated with colon cancer risk. In contrast, Xu et al., (2007) reported an increased breast cancer risk in women with this gene deletion. Corroborating our findings, one study evaluated the DHFR 19-pb ins/del (rs70991108) polymorphism in mother/child dyads in acute lymphoblastic leukemia onsetlatency and demonstrated a good prognosis for carrier patients with homozygous deletion (Tisato et al., 2019).

The role of TYMS 28-bp tandem repeat polymorphisms was not associated with acute lymphoblastic leukemia and lung cancer risk development (Oosterom et al., 2018; Stanisławska-Sachadyn et al. 2019); however, a study in the Brazilian population revealed increased risk association between the $2 \mathrm{R} / 2 \mathrm{R}$ and $2 \mathrm{R} / 3 \mathrm{R}$ variants in sporadic and hereditary breast cancer development, which was not in accordance with the results of our study (da Silva Nogueira et al., 2012).

In our study, the SHMT1 1420C/T (rs1979277) polymorphism had no association with head and neck cancer risk; however, it was associated with tumor progression. The human SHMT1 gene is located at chromosome $17 \mathrm{p} 11.2$; the cytosolic isoform and its coenzyme, vitamin B6, catalyze the reversible conversion of serine and tetrahydrofolate to glycine and 5,10-methylene tetrahydrofolate that provide one-carbon units during pyrimidine and purine syntheses (Coppedè et al., 2019). A meta-analysis revealed that no association was found between SHMT1 1420C > T (rs1979277) and the overall risk of cancer; however, in the subgroup analysis, significant associations with a protective effect were found in colorectal cancer and in the Asian population (Wang et al., 2014).

A preliminary study by our research group also found no risk association with head and neck cancer in the Brazilian population (Succi et al., 2014), which was in accordance with the results obtained for gastric cancer (Kim et al., 2016), colorectal cancer (Komlósi et al., 2010), non-Hodgkin lymphoma (Skibola et al., 2004), lung cancer (Wang et al., 2014), and breast cancer (Lissowska et al., 2007). According to Cheng et al., (2008), mutations in SHMT1 leading to an aberrant protein can be compensated for by the wild-type SHMT2 gene that encodes an isoform with the same function.

This is the first study to demonstrate an association between survival and relapse-free times. Individuals with wild-type genotype, DNMT3B -579 $G / G$, have longer survival times in relation to $D N M T 3 B-579 T$ carriers, and this is also true for TYMS-3R carriers with respect to the TYMS-2R/2R genotype. Moreover, this last polymorphism protects $T Y M S-3 \mathrm{R} / 3 \mathrm{R}$ genotype carriers against cancer recurrence. In vitro and in vivo studies have been carried out to verify the functional consequences of the variable number of tandem repeat polymorphism. In general, the $T Y M S$ alleles contain two or three copies of repeats $(2 R$ and $3 R$ ), and the $T S$ genes with triple sequence have higher expression levels than those with double sequence, and thus have transcriptional activity with the $3 \mathrm{R}$ sequence, which can be three to four times greater than that with the 2R carriers (Gusella and Padrini, 2007).

A previous study that involved a smaller number of head and neck cancer patients evaluated survival and relapse-free time for the DNMT3B 46359C/T and SHMT1 $1420 \mathrm{C} / \mathrm{T}$ polymorphisms, but failed to demonstrate any statistically significant association between the wild-type and polymorphic carriers (Succi et al., 2014). In the present study, no association was observed between the SHMT1 1420C/T polymorphism and survival time and relapse-free cancer.

Thus, our findings reveal that DNMT3B $-283 T / C$ is associated with cancer risk, whereas DHFR 19-pb ins/ del and TYMS 28-bp tandem repeat polymorphisms have a protective effect against head and neck cancer in relation to that in the control group. Furthermore, we highlight the association of the TYMS $3 R / 3 R$ genotype with relapse-free cancer protection and the increased survival time of these patients in relation to those with the TYMS $2 \mathrm{R}$ allele.

\section{Acknowledgements}

The authors are grateful to Lilian Castiglione for her Asian Pacific Journal of Cancer Prevention, Vol 213757 
support with the statistical analysis, the participating patients, their families and to the team of the Biological and Genetics and Molecular Biology Research Unit-UPGEM. The authors also thank the financial support of the Foundation for Research Support of the State of São Paulo - FAPESP (2010/00012-0 and 2011/17886-6), the Coordination for the Improvement of Higher Education Personnel - CAPES (Financial Code 001) and National Council for Scientific and Technological Development - CNPq (Process n ${ }^{\circ}$ 310987/2018-0), and FAMERP/ FUNFARME support.

\section{Author Contributions}

Eny Maria Goloni-Bertollo, Érika Cristina Pavarino, and Tialfi Bergamin de Castro devised and designed the experiments. Tialfi Bergamin de Castro, Jéssika Nunes Gomes da Silva, Fabia Pigatti Silva, and Gabriela Helena Rodrigues-Fleming performed the experiments. Ana Lívia Silva Galbiatti-D provided technical support. Juliana Garcia de Oliveira-Cucolo, Tialfi Bergamin de Castro Serafim, and Gabriela Helena Rodrigues-Fleming analyzed and interpreted the data. Eny Maria GoloniBertollo, Luiz Sérgio Raposo, and José Victor Maniglia contributed to the collection of samples/reagents/materials and analysis tools. Juliana Garcia de Oliveira-Cucolo, Gabriela Helena Rodrigues-Fleming, Érika Cristina Pavarino, and Eny Maria Goloni-Bertollo drafted and revised the manuscript. All the authors approved the final version of the manuscript for publication.

\section{Institutional Review Board Statement}

This study was approved by the local Research Ethics Committee (registration number: 013/2012).

\section{Informed Consent Statement}

The participants provided written informed consent for data sharing.

\section{Statement conflict of Interest}

The authors declare no conflicts of interest.

\section{References}

Barrett JC (2009). Haploview: Visualization and analysis of SNP genotype data. Cold Spring Harb Protoc, 2009, pdb.ip71.

Canova C, Richiardi L, Merletti, F, et al (2010). Alcohol, tobacco and genetic susceptibility in relation to cancers of the upper aerodigestive tract in northern Italy. Tumori, 96, 1-10.

Cheng CW, Yu JC, Huang CS, et al (2008). Polymorphism of cytosolic serine hydroxymethyltransferase, estrogen and breast cancer risk among Chinese women in Taiwan. Breast Cancer Res Treat, 111, 145-55.

Chow LQM (2020). Head and Neck Cancer. $N$ Engl J Med, 382, 60-72.

Cohen N, Fedewa S, Chen AY (2018). Epidemiology and demographics of the head and neck cancer population. Oral Maxillofac Surg Clin North Am, 30, 381-95.

Coppedè F, Stoccoro A, Tannorella P, et al (2019). Association of polymorphisms in genes involved in one-carbon metabolism with. Int J Mol Sci, 20.

da Silva Nogueira J, de Lima Marson FA, Sílvia Bertuzzo C (2012). Thymidylate synthase gene (TYMS) polymorphisms in sporadic and hereditary breast cancer. BMC Res Notes,

\section{$5,676$.}

Duan F, Cui S, Song C, et al (2015). Systematic evaluation of cancer risk associated with DNMT3B polymorphisms. $J$ Cancer Res Clin Oncol, 141, 1205-20.

Fan C, Yu S, Zhang S, et al (2017). Association between folate intake and risk of head and neck squamous cell carcinoma: An overall and dose-response PRISMA meta-analysis. Medicine (Baltimore), 96, e8182.

Fanidi A, Relton C, Ueland PM et al (2015). A prospective study of one-carbon metabolism biomarkers and cancer of the head and neck and esophagus. Int J Cancer, 136, 915-27.

Galeone C, Edefonti V, Parpinel M, et al (2015). Folate intake and the risk of oral cavity and pharyngeal cancer: a pooled analysis within the International Head and Neck Cancer Epidemiology Consortium. Int J Cancer, 136, 904-14.

Gusella M, Padrini R (2007). "G>C SNP of thymidylate synthase with respect to colorectal cancer. Pharmacogenomics, 8 , 985-96.

IARC IAfRoC- (2019). World Health Organization. Global Cancer Observatory-Globocan.”https://gco.iarc.fr/.

Jokić M, Brčić-Kostić K, Stefulj J, et al (2011). Association of MTHFR, MTR, MTRR, RFC1, and DHFR gene polymorphisms with susceptibility to sporadic colon cancer. DNA Cell Biol, 30, 771-6.

Kim W, Woo HD, Lee J, et al (2016). Dietary folate, one-carbon metabolism-related genes, and gastric cancer risk in Korea. Mol Nutr Food Res, 60, 337-45.

Komlósi V, Hitre E, Pap E, et al (2010). SHMT1 1420 and MTHFR 677 variants are associated with rectal but not colon cancer. BMC Cancer, 10, 525 .

Li H, Li W, Liu S, et al (2016). DNMT1, DNMT3A and DNMT3B polymorphisms associated with gastric cancer risk: A Systematic Review and Meta-analysis. EBioMedicine, 13, 125-31.

Lissowska J, Gaudet MM, Brinton LA, et al (2007). Genetic polymorphisms in the one-carbon metabolism pathway and breast cancer risk: a population-based case-control study and meta-analyses. Int J Cancer, 120, 2696-2703.

Liu AY, Scherer D, Poole E, et al (2013). Gene-diet-interactions in folate-mediated one-carbon metabolism modify colon cancer risk. Mol Nutr Food Res, 57, 721-34.

Liu W, Zhou H, Zhu Y et al (2017). Associations between dietary folate intake and risks of esophageal, gastric and pancreatic cancers: an overall and dose-response meta-analysis. Oncotarget, 8, 86828-42.

Miller SA, Dykes DD, Polesky HF (1988). A simple salting out procedure for extracting DNA from human nucleated cells. Nucleic Acids Res, 16, 1215.

Ni Y, Du J, Yin X, et al (2019). Folate intake, serum folate, and risk of esophageal cancer: a systematic review and doseresponse meta-analysis. Eur J Cancer Prev, 28, 173-80.

Oosterom N, Berrevoets M, den Hoed MAH, et al (2018). The role of genetic polymorphisms in the thymidylate synthase (TYMS) gene in methotrexate-induced oral mucositis in children with acute lymphoblastic leukemia. Pharmacogenet Genomics, 28, 223-9.

Pieroth R, Paver S, Day S, et al (2018). Folate and its impact on cancer risk. Curr Nutr Rep, 7, 70-84.

Rettig EM, D'Souza G (2015). Epidemiology of head and neck cancer. Surg Oncol Clin N Am, 24, 379-96.

Skibola CF, Forrest M S, Coppedé F, et al (2004). Polymorphisms and haplotypes in folate-metabolizing genes and risk of non-Hodgkin lymphoma. Blood, 104, 2155-62.

Solé X, Guinó E, Valls J, et al (2006). SNPStats: a web tool for the analysis of association studies. Bioinformatics, 22, 1928-9.

Stanisławska-Sachadyn A, Borzyszkowska J, Krzemiński M, et 
al (2019). Folate/homocysteine metabolism and lung cancer risk among smokers. PLoS One, 14, e0214462.

Succi M, de Castro TB, Galbiatti AL, et al (2014). DNMT3B C46359T and SHMT1 C1420T polymorphisms in the folate pathway in carcinogenesis of head and neck. Mol Biol Rep, 41, 581-9.

Tio M, Andric J, Cox MR, et al (2014). Folate intake and the risk of prostate cancer: a systematic review and meta-analysis. Prostate Cancer Prostatic Dis, 17, 213-9.

Tisato V, Muggeo P, Lupiano T, et al (2019). Maternal Haplotypes in. Genes (Basel), 10.

Wang Q, Lu K, Du H, et al (2014). Association between cytosolic serine hydroxymethyltransferase (SHMT1) gene polymorphism and cancer risk: a meta-analysis. Biomed Pharmacother, 68, 757-62.

Wang TH, Hsia SM, Shih YH, et al (2017). Association of smoking, alcohol use, and Betel Quid chewing with epigenetic aberrations in cancers. Int J Mol Sci, 18.

Xu X, Gammon MD, Wetmur JG, et al (2007). A functional 19-base pair deletion polymorphism of dihydrofolate reductase (DHFR) and risk of breast cancer in multivitamin users. Am J Clin Nutr, 85, 1098-1102.

Zeng J, Gu Y, Fu H, et al (2020). Association between one-carbon metabolism-related vitamins and risk of breast cancer: A Systematic Review and Meta-analysis of Prospective Studies. Clin Breast Cancer, 2020.

Zhang Y, Xu H, Shen Y, et al (2015). Association of DNMT3B $-283 \mathrm{~T}>\mathrm{C}$ and $-579 \mathrm{G}>\mathrm{T}$ polymorphisms with decreased cancer risk: evidence from a meta-analysis. Int J Clin Exp Med, 8, 13028-38.

Zhou X, Meng Y (2016). Association between serum folate level and cervical cancer: a meta-analysis. Arch Gynecol Obstet, 293, 871-7.

\section{(ब) $(\mathbb{8}$}

This work is licensed under a Creative Commons AttributionNon Commercial 4.0 International License. 